\title{
PRECISION THICKFILM ACTIVE RC FILTERS
}

\author{
E. MÜLLER, M. GLOGER, E. SCHMIDT and W. ULBRICH \\ Lehrstuhl für Netzwerktheorie und Schaltungstechnik, Technische Universität München, \\ München F.R. Germany.
}

(Received February 21, 1980)

\begin{abstract}
The application of hybrid thickfilm technology to the realization of precise active RC filters with passband frequencies up to $3.5 \mathrm{kHz}$ is described and it is shown that relatively expensive thin-film technology can often be replaced by the simpler thickfilm process.
\end{abstract}

\section{INTRODUCTION}

In this paper the application of hybrid thickfilm technology for realizing precise active RC filters with passband frequencies up to $3.5 \mathrm{kHz}$ is described.

The following examples of filters used in communication and audio-frequency measurement systems show that relatively expensive thinfilm technology can be replaced by the simpler thickfilm process in several cases.

The circuit design procedure has to take the thickfilm properties into account and a great amount of effort is required to reduce the sensitivities of the attenuation with respect to component variations. Because of their low-sensitivity properties doublyterminated LC-prototypes ${ }^{1}$ are used for the active simulation.

\section{GYRATOR PCM LOWPASS FILTER}

In order to simulate the grounded or floating inductors of the 5th-order elliptic LC lowpass (LP)

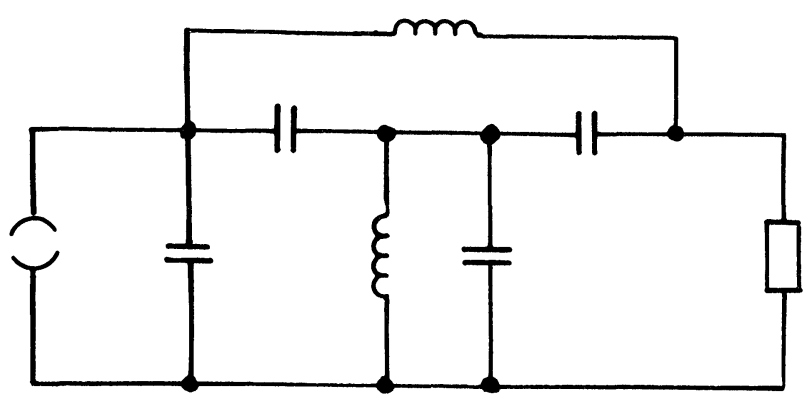

FIGURE 1 LC-prototype for the gyrator PCM LP filter. filter shown in Figure 1 by gyrators and capacitors, two gyrators are realized on 0.33 in $x \dot{1}$ in substrates by blocks. These circuits consist of two or three op-amps and eight or ten resistors, respectively. Figure 2 shows these building blocks. The capacitors are to be connected externally in the case of a CCITT PCM LP filter because of the high price and the required volume of $\pm 1 \%$ chip-capacitors with element values from $2.5 \mathrm{nF}$ to $11.2 \mathrm{nF}$. Only one resistor ink $(10 \mathrm{kohm} / \square)$ is used. The cuts were trimmed automatically by a YAG-laser system ${ }^{2}$ and, by a proper selection of the geometries, an R-accuracy of $\pm 2 \%$ o can be achieved. ${ }^{3}$ For $R_{\min }=3.16 \mathrm{kohm}$ and $\mathrm{R}_{\max }=27.2 \mathrm{kohm}$ an R-accuracy of $\pm 5 \%$ o (including the long-time stability) is obtained. The entire active filter circuit (see Figure 3) consists of five op-amps, eighteen resistors and six capacitors. The measured attenuation curves are shown in Figure 4 together with the attenuation restrictions.

\section{PCM LP FILTER SIMULATING THE SIGNAL- FLOW GRAPH (SFG) OF AN LC-PROTOTYPE}

To obtain an active circuit with a minimum number of capacitors, the SFG of the elliptic LC filter in Figure 5 (refer to Saal and Entenmann ${ }^{4}$ ) is simulated by a canonical circuit. ${ }^{5}$ In order to reduce the number of printing processes a universal layout ( 0.5 in $\times 1$ in) is used for two subcircuits. By laser cutting of conductive paths the layout is adapted to the special requirements. Seven op-amps are ultrasonic wire-bonded and the five chip-capacitors are connected with a printed solder paste. One of the advantages of this filter concept is that only the RCproduct of each integrator influences the frequency 

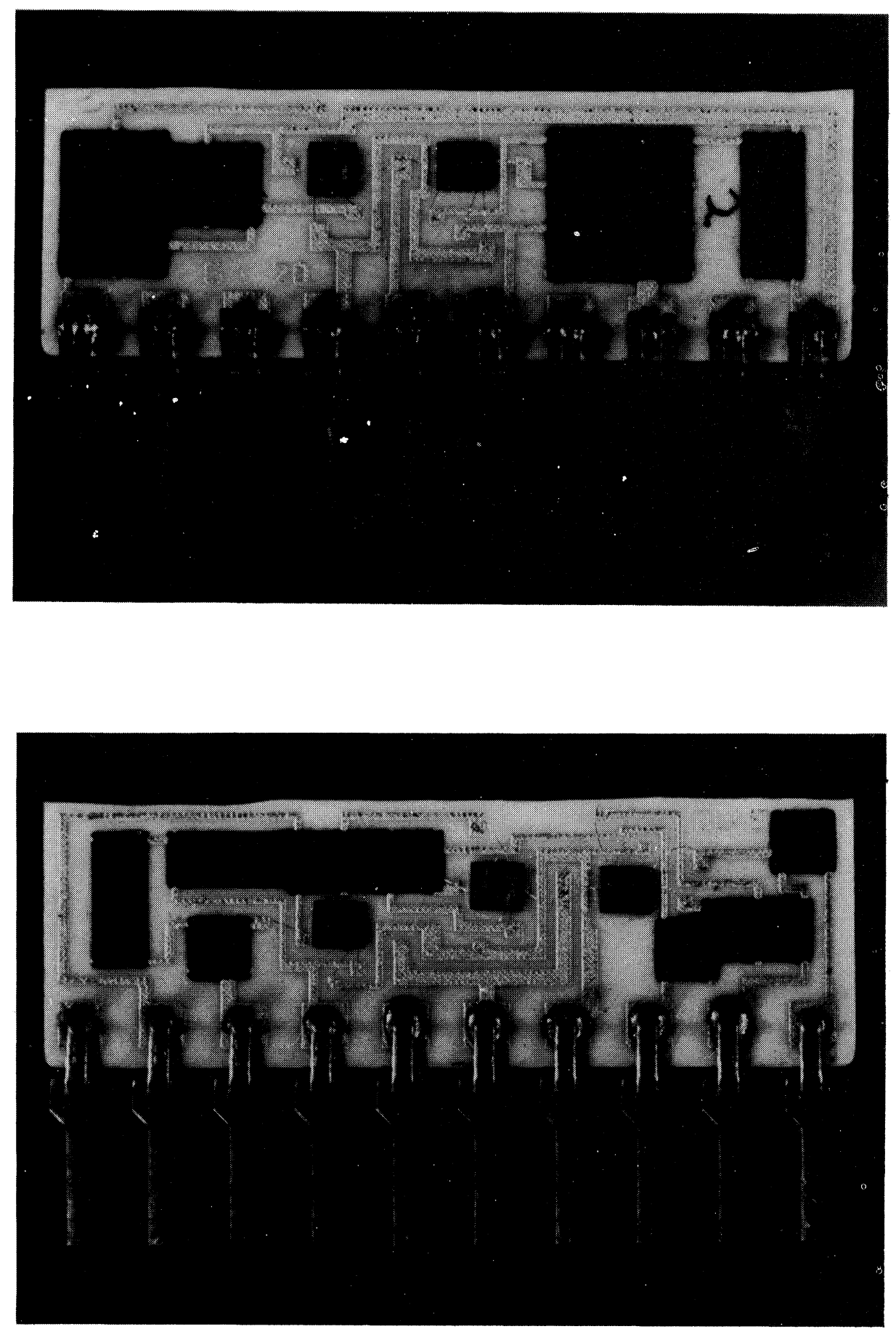

FIGURE 2 Gyrator circuits for the simulation of grounded (a) and floating inductors (b). 


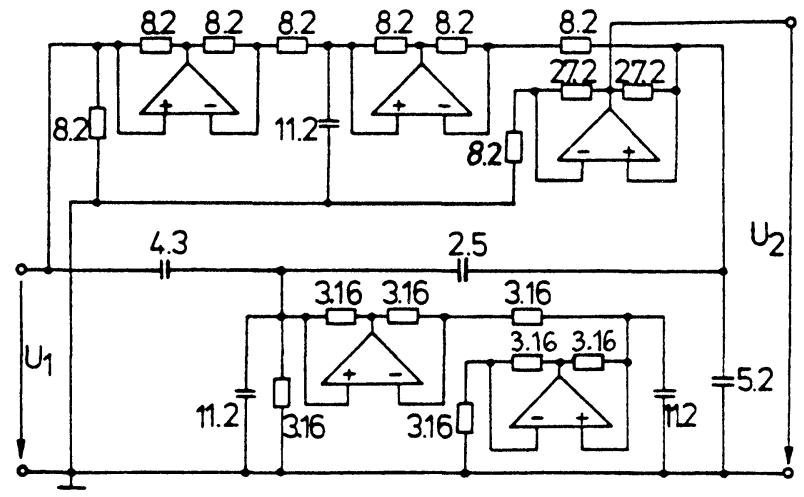

FIGURE 3 Circuit of the gyrator PCM LP filter ( $R$ in kohm, C in $n F$, used op-amps $\mu \mathrm{A}$ 741).

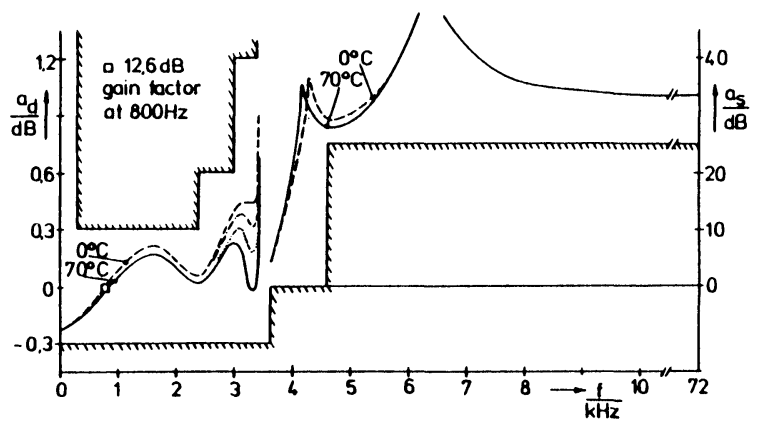

FIGURE 4 Measured attenuation curves of the gyrator PCM LP filter.

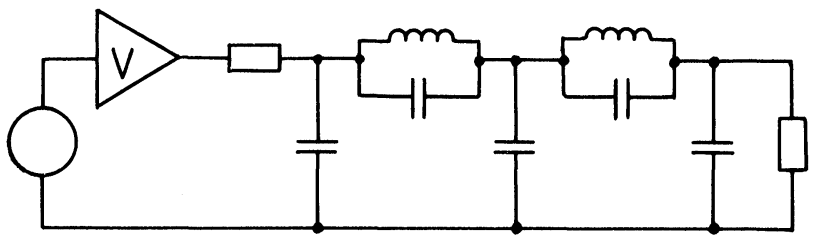

FIGURE 5 LC-prototype of the SFG PCM LP filter with additional amplifier. $V=4.266, V=12.6 \mathrm{~dB}$.

response of the filter. Thus roughly tolerated capacitors and adapted laser-trimmed resistors yield the required time constants $T_{i}=R_{i} C_{i}$. Two resistor inks $(10 \mathrm{kohm} / \square, 50 \mathrm{kohm} / \square)$ and five chip-capacitors with equal values of $\mathrm{C}=680 \mathrm{pF} \pm 10 \%$ are used.

Figure 6 shows the photograph of one subcircuit, of the complete PCM LP filter circuit is shown in Figure 7, while the measured attenuation curves of this filter are shown in Figure 8.

\section{VARIABLE OCTAVE FILTER}

A variable 6th-order bandpass filter with specially approximated attenuation curves is designed to satisfy the requirements of DIN 45651 (see Figure 9) for octave filters with centre frequencies in the range from $10 \mathrm{~Hz} \leqslant \mathrm{f}_{\mathrm{m}} \leqslant 1 \mathrm{kHz}$. The lowpassbandpass transformation is applied to the SFG of



FIGURE 6 Subcircuit for the SFG PCM LP filter. 


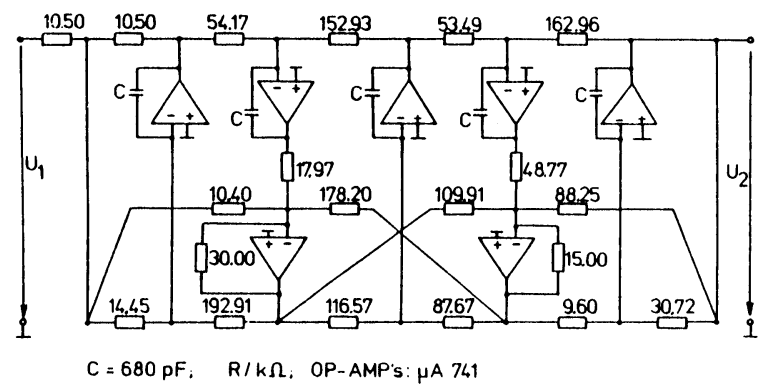

FIGURE 7 Circuit of the SFG PCM LP filter.

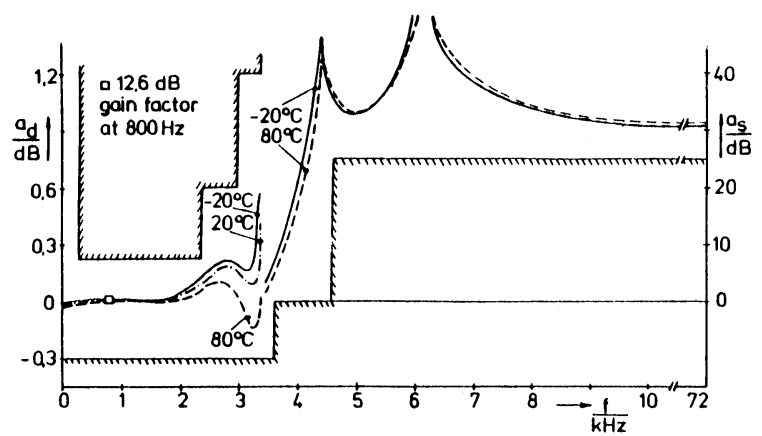

FIGURE 8 Measured attenuation curves of the SFG PCM LP filter.

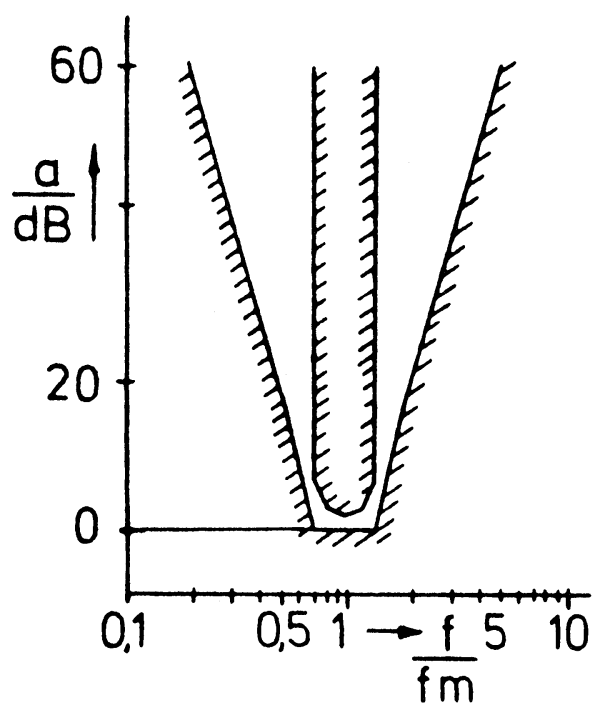

FIGURE 9 Attenuation requirements for octave filters (DIN 45 651).

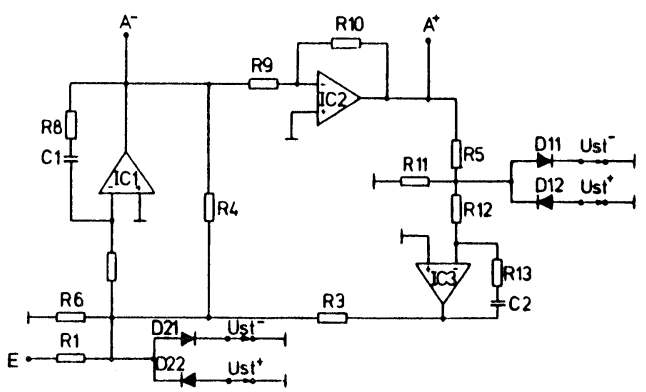

FIGURE 10 Variable 2nd-order analogue-computer bandpass filter circuit.

the reference LC lowpass filter. The resulting secondnrder transfer functions are realized separately on 0.5 in $\times 1$ in substrates using the analogue-computer principle. A voltage-controlled network containing resistors and pn junction diodes (connected in odd symmetrical pairs) allows the variation of the centre frequency. The bonding and soldering processes are the same as in the preceding examples. Additional layout problems caused by the fixed pin sequence requires a two-layer technique. Two prints of the insulating material separate the layers. Figure 10 shows a second-order section with four pn junction diodes. The realization of a second-order bandpass filter section is shown in Figure 11. Measured attenuation curves with the control voltage $\mathrm{U}_{\mathrm{St}}$ as a parameter are shown in Figure 12.

\section{CONCLUSION}

In all cases mentioned in the preceding sections functional trimming can be avoided because the accuracy of thickfilm resistors $\left(\Delta \mathrm{R} / \mathrm{R} \approx 5 \% \mathrm{TK}_{\mathrm{R}} \approx\right.$ $100 \mathrm{ppm} / \mathrm{K}$ ) yields very stable attenuation curves in view of the low-sensitivity properties of activesimulated terminated LC filter circuits. Within the temperature range from $0^{\circ} \mathrm{C}$ to $+70^{\circ} \mathrm{C}$, both the gyrator filter and the SFG filter meet the requirements very well. Their excellent dynamic range of more than $100 \mathrm{~dB}$ (power consumption $\approx 250 \mathrm{~mW}$ $\mathrm{V}_{\mathrm{CC}}= \pm 15 \mathrm{~V}$ ) should be mentioned especially. The proposed octave filter allows a continuous variation of the centre frequency by a factor of 100 without violating the tolerance requirements. 


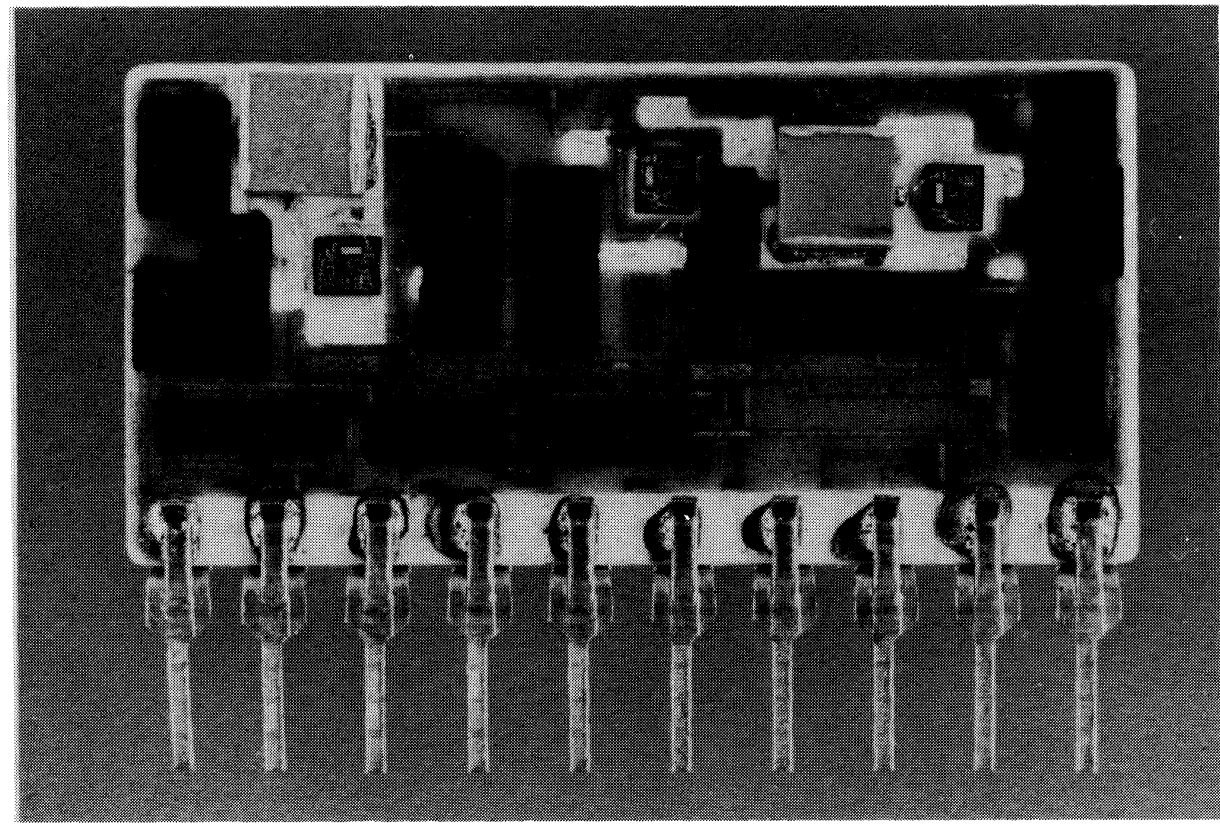

FIGURE 11 Analogue-computer bandpass filter circuit.

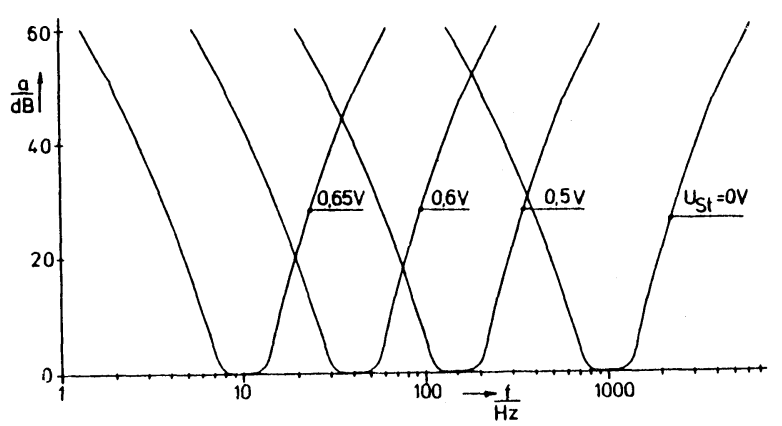

FIGURE 12 Measured attenuation curves of an octave filter $\left(\vartheta=20^{\circ} \mathrm{C}\right)$.

\section{REFERENCES}

1. H. J. Orchard, "Inductorless filters." Electron. Lett. 2 (1966), pp. 224-225.

2. E. Schmidt, "Trimmen von Schichtwiderständen mit einem automatischen Laser-Abgleichsystem." Funktechnik 34 (1979), pp. T36-T43.

3. W. Ulbrich, "Resistor geometry comparison with respect to current noise and trim sensitivity." Proc. Europ. Hybrid Microelectronic Conf. 1977, pp. XV-1/XV-8.

4. R. Saal, W. Entenmann, Handbuch zum Filterentwurf (Elitera, Berlin, 1979).

5. E. Müller, Mehrfach rückgekoppelte akitive RC-Filterschaltungen. Diss. Technische Universität München, 1979. 

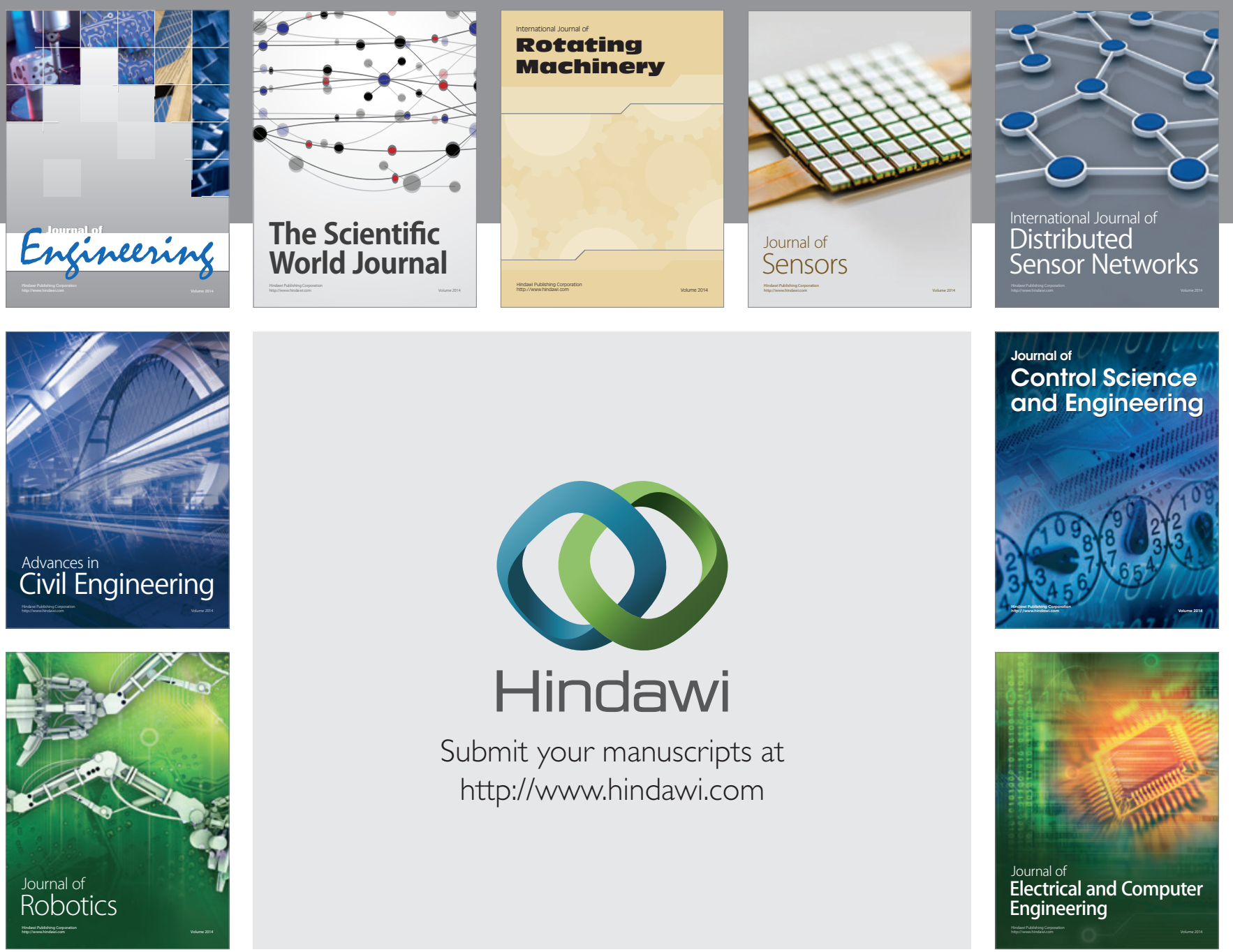

Submit your manuscripts at

http://www.hindawi.com
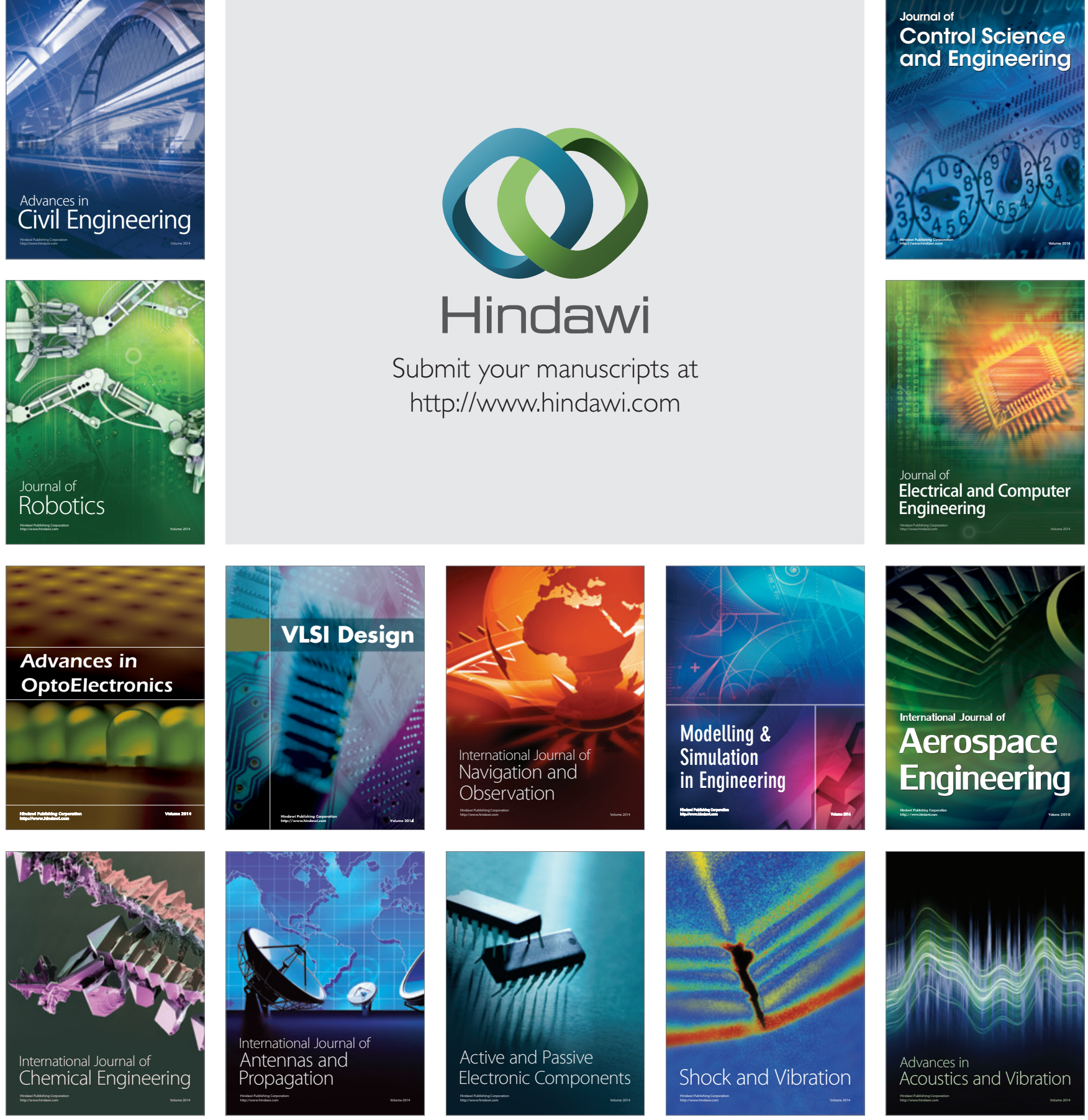